\title{
Research and Application of PIMS in Automobile Tire Tread Production $\mathrm{Na} \mathrm{Liu}^{1, \mathrm{a}}$, Kai Yang ${ }^{1, \mathrm{~b}}$, Zelin $\mathrm{Li}^{1, \mathrm{c}}$, Xiangguang Chen ${ }^{\star, 1, \mathrm{~d}}$, Xiaoli Ma $\mathrm{Ma}^{1, \mathrm{e}}$ \\ ${ }^{1}$ School of Chemical Engineering and Environment, Beijing Institute of Technology, Beijing, 100081 ,China

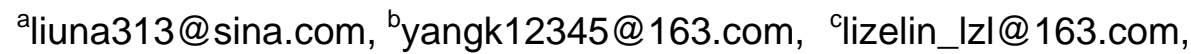 \\ *,Corresponding, Author, ${ }^{d} x g c 1 @$ bit.edu.cn, ${ }^{e}$ maxiaoli@bit.edu.cn
}

Keywords: Tire Tread Production, Process Information Management System (PIMS), B/S, C/S, SQL Server.

\begin{abstract}
In order to improve the information management level in the process of automobile tire tread production, the actual condition for the tire production process is analyzed in this paper. The information management system of the extruding line in the process of automobile tire tread manufacturing is designed based on combination of $\mathrm{B} / \mathrm{S}$ and $\mathrm{C} / \mathrm{S}$ models. The system uses a large-scale distributed database SQL Server 2008 R2 as the underlying database, the C/S section uses visual studio 2012 as a development tool, .NET Framework 4.5 for development environment, C\# language for programming which is an object-oriented programming language to complete the development of the client program. The B/S section uses the Apache server as a web server, the popular web authoring tool Dreamweaver as a development tool, and PHP language as the programming language to complete the program. The application results in real field show that the information management system proposed in this paper based on the combination of $\mathrm{C} / \mathrm{S}$ and $\mathrm{B} / \mathrm{S}$ models can meet the needs of automobile tire production process, and the process information management system has good application value.
\end{abstract}

\section{Introduction}

In recent years, with the rapid development of computer technology development and manufacturing process of information technology, the information management level of industrial processes has been greatly improved, such as the petrochemical, pharmaceutical and food industry. The tire is one of the most important components of a vehicle [1], and information management systems for automobile tire production process needs to be further developed and improved. In the automobile tire production process, the tire manufacturing process controlling, quality inspection and quality tracking, and acquisition and storage of the production information play important roles [2]. Therefore, as the requirements of auto industry for carbon emissions, energy conservation, environmental protection, safety performance, etc. continuing to increase, meanwhile the tire is an important part for automobile [3], how to use the advanced information management tools to improve the quality and yield of the products and to achieve the goal of energy saving technology innovation in tires production process has become an urgent problem to be solved.

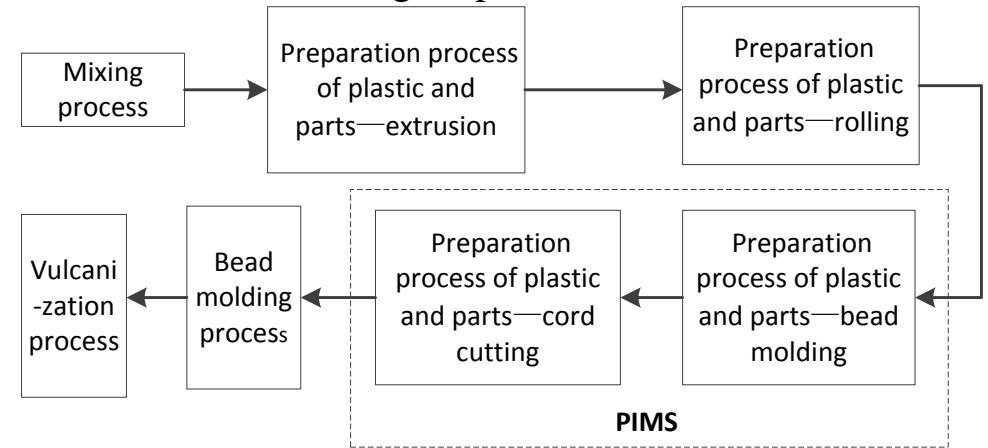

Figure 1. Production process of automobile tire 
Automobile tire production process is characterized by high temperature and pressure, explosive, and increased use of the boiler, lifting equipment and forklifts, etc[4]. Medium-sized enterprises in the production of tire production sector have many staff members, the production process is complex, as shown in Figure 1, and on-site production lines for the production are all-weather, which determines that the safety management of tire production process is more difficult and complex.

Therefore, the development of a process information management system in automobile tire tread has great significance. The process information management system (PIMS) of automobile tire tread production is developed in this paper and has been applied into the actual production process.

$\mathrm{B} / \mathrm{S}$ network model is a browser/server model based on the needs of Intranet. Because the database has powerful features, such as data storage and management capabilities, dynamic data input and output capabilities [5], the integrated database and Intranet can not only achieve a lot of information available online, but also provide dynamic data query and processing functions for the majority of users.

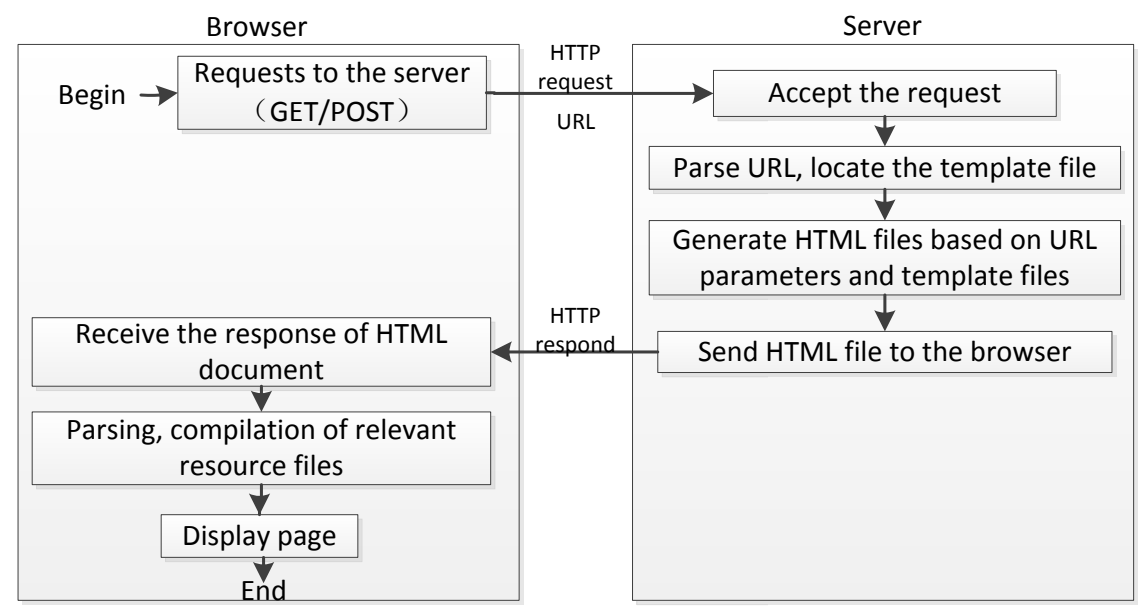

Figure 2. Implementation principle of B/S model

In the $\mathrm{B} / \mathrm{S}$ model, the web client runs the browser software, the browser make a request to the Web server to access the data in the form of hypertext browser, the request method is divided into POST and GET, for the GET request, the browser is actually a URL request, the variable names and contents are included in the URL. The client browser parses the server's response to be displayed in the form of web page [6], as showed in Figure 2. With this structure, system upgrades and ongoing maintenance are more convenient and faster, we can achieve "an installation available anywhere"[7].

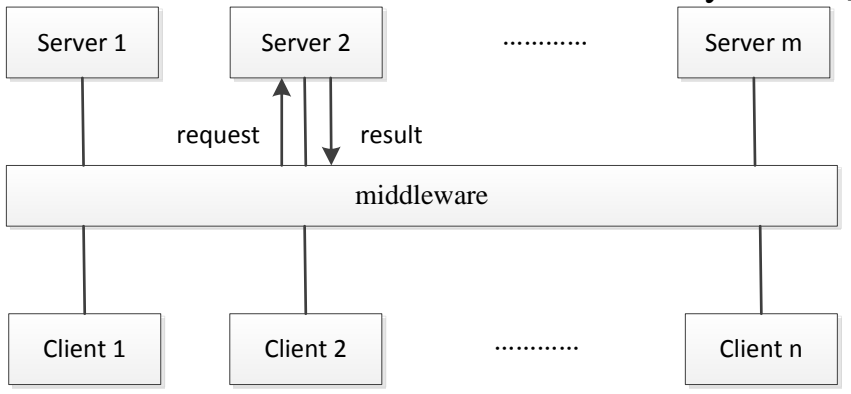

Figure 3. Work principle of B/S model

The fundamental principle of C/S structure is to decompose the computer application tasks into multiple sub-tasks. The division is completed by multiple computers, namely "distribution function" principle. $\mathrm{C} / \mathrm{S}$ model is determined by the client and server together to achieve a collaboratively two-story structure model. And it is mainly composed of the client application (Client), server management program (Server) and middleware (Middleware) three components. The client, server, and middleware connecting them together complete a certain task proposed in collaboration [8], as shown in Figure 3. In this structure, the server operating pressure of is relatively small and the security is better [9]. 


\section{Analysis and Design for Information Management System’s Functions}

This paper is based on the field process of two tread production lines, the 3rd and the 5th line of the tread production line, these two lines have been provided with a tread scale line monitoring system, and the data like the weight of tread from the tread scale can be collected to field IPC. The overall structure of the field system is shown in Figure 4.

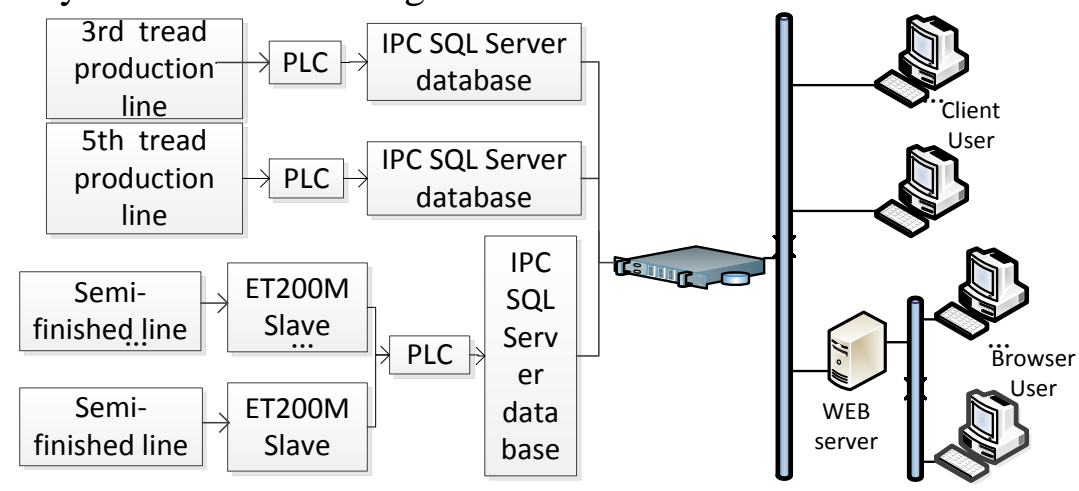

Figure 4. PIMS in tire tread production

The hardware configuration and interface are equipped in this two tread production line, while the ET200M slaves collect production data to IPC from semi-finished wire. Then the data like screw speed, meter scale value, the host speed, auxiliary line speed, discharge temperature data, production specifications, production time, etc. are collected and input to PLC. Then the related data collected from PLC is stored into the server database by the upper computer to complete acquiring the information from the field production process.

Based on the needs of the production plant, we choose the design approach with two models combined, which gives full play to the advantages of the two models for the design of information management systems and makes mutual constraints and interconnected parts of a system constituting a complete information management system.

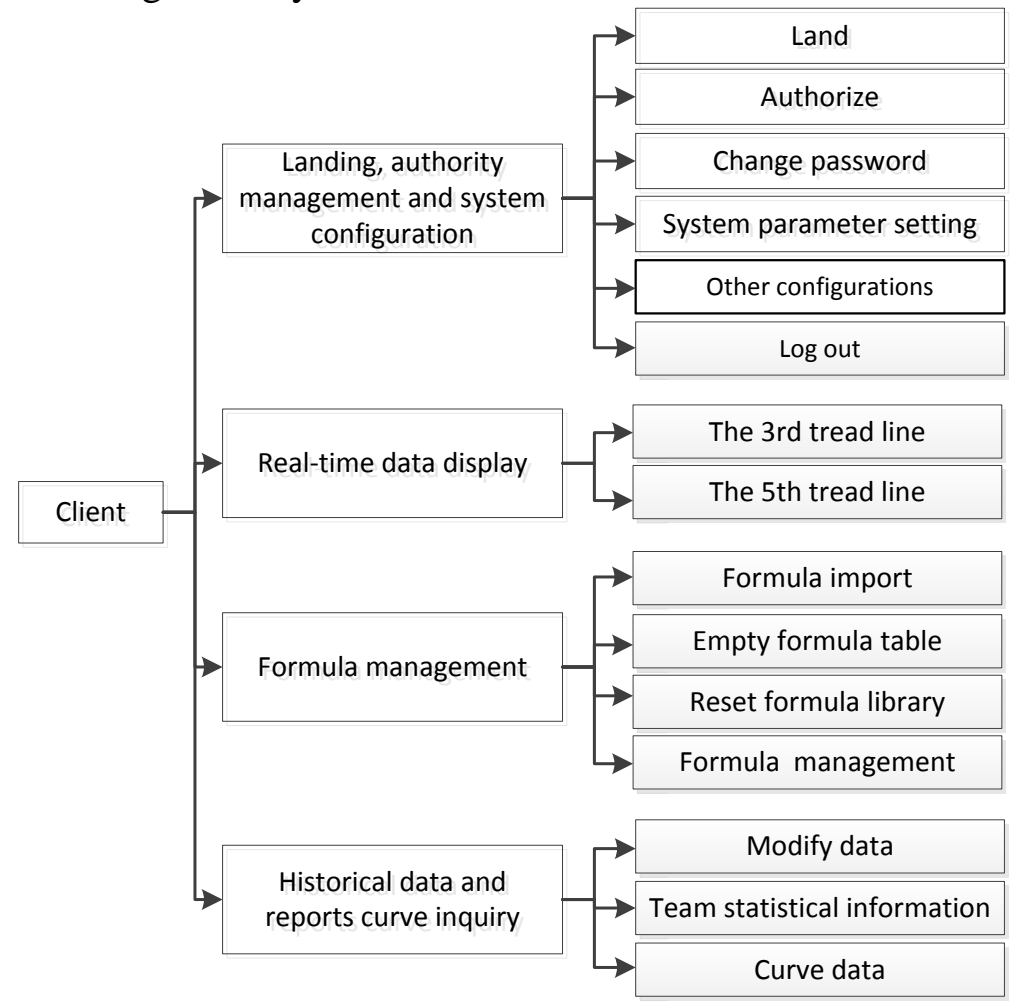

Figure 5. PIMS function module based on C/S model

The client part is mainly used for real-time data displaying, formula management, logging off and landing rights management, historical data query and reporting curve, etc. And this section is a large 
production line data management system. Its processing content involves each aspects of the production line, which required good interactivity and high security of the system. Meanwhile because of the frequent exchange of data with the database, strong data processing capabilities and database security constraints were needed. The most significant feature of C/S model is that the client makes requests and the server provides services, which make up the shortcomings of a bad computing power and unevenly distributed resources [10]. The function of the client part can be divided into four parts. Each part can be divided into several smaller functional modules. The functional modules may appear different after the different user logs in. For the overall design of the C/S functional section, its functional module is shown in Figure 5.

The B/S web client part is mainly used for displaying real-time production curve of the two tire tread production lines, such as the curve of the weight of tread, and the real-time production formulas parameters and other parameters. This project involves two tire tread production lines. In this part the main need is to real-time display the comparing graph and production data of the weight of the tread with the production parameters such as the meter scale value, the host speed, production time, production formula. The most important requirement is that any user within the LAN can view this part with a computer in which a browser has been installed.

For the overall design of the B/S section, its functional module is shown in Figure 6.

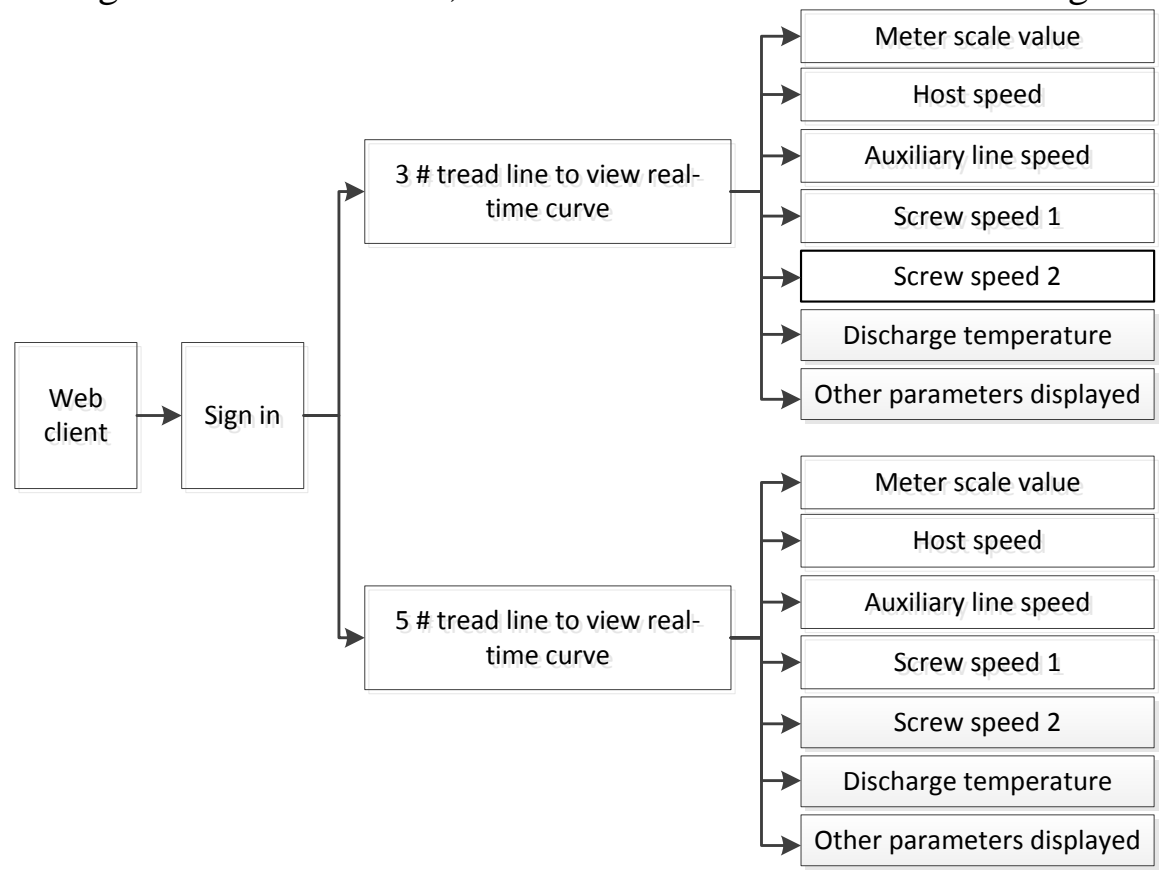

Figure 6. PIMS function module based on B/S model

\section{Implementation and Application of PIMS}

The database design is the core of the whole system. The two field tread production lines at the IPC use two independent database servers, and a comprehensive database server is installed in the control room, consisting of a large distributed type of database system [11]. The database throughout the system connected the database dispersed in each network node by network communication technology. In order to facilitate inquiring and follow-up managing, the three database servers have used the same design approach. And all of them have chosen SQL Server 2008R2 database for database system, used windows authentication and SQL Server authentication system, making the system safer, reliable and expansible.

The C/S client part is mainly applied to information management for tread production line. The C/S part has used the large-scale distributed database SQL Server 2008R2 as the underlying database, visual studio 2012 as a development tool, .NET Framework 4.5 for development environment, C\# object-oriented programming language to develop the corresponding function modules to achieve all function. The implementation process based on C/S model is shown in Figure 7. 


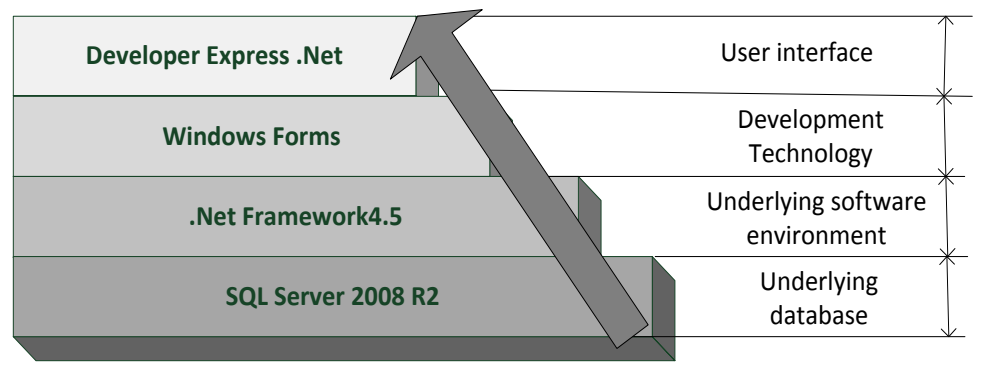

Figure 7. Implementation process based on C/S model

The web client was mainly for real-time data displaying of the production line and user login and logout, a user could only view the data and curve of the field production line after landing. This section has taken the Apache server as a Web server, the popular web authoring tool Dreamweaver at the front desk as a development tool, the PHP language as programming language, SQL Server 2008 R2 database as the backend database, which finally completed dynamic interactive features of the web client. The implementation process based on B/S model is shown in Figure 8.

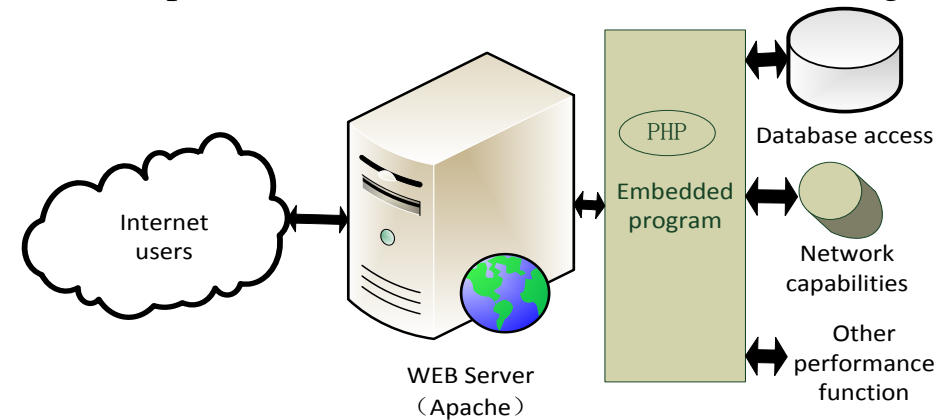

Figure 8. Implementation process based on B/S model

The web interface presented to the internet users is the user presentation layer. Internet users use the browser to make service requests to the Web server through the Internet or public Intranet. Server-side scripting code is based on the .NET Framework and the ASP.NET code of CLR (Common Language Runtime), web server mainly completed the collection of information from the user and a simple sort, and then sent the information into the database. The processed data were stored by the database server. The interaction between the two servers was via the network.

\section{Conclusions}

This paper analyzes the actual condition of the tire manufacturing process. According to the characteristics of the tread production line of the tire manufacturing process, a combination of $\mathrm{B} / \mathrm{S}$ and $\mathrm{C} / \mathrm{S}$ models is used to design the process information management system in the automobile tire tread production. The system uses a large-scale distributed database SQL Server 2008 R2 as the underlying database. The C/S section uses .NET Framework 4.5 for development environment to complete the development of the client program, the B/S section uses Apache server as a Web server to complete web section program, which will overcome the inadequacy of single model and complement the advantages of each single model efficiently. The system has completed the needs of the enterprise in the process of automobile tire tread production.

\section{Acknowledgments}

The research work was supported by Beijing Research \& Design Institute of Rubber Industry, Beijing 100143, China.

\section{References}

[1] Yang N., Chen D., Hu S., Li Y. and Jin Y.. Evaluation of the Tire Industry of China based on Physical Input-Output Analysis[J]. Journal of Industrial Ecology, 2010, 14(3): 457-466. 
[2] Shan C., Gu Z., Wang L., Li P., Song G., Gao Z. and Yang X.. Preparation, characterization, and application of NR/SBR/Organoclay nanocomposites in the tire industry[J]. Journal of Applied Polymer Science, 2011, 119(2):1185-1194.

[3] Chen Xiaowen. Ren Long. The green production management model of export tire and recommendations on standards[J]. World Rubber Industry, 2012, 39(11):1-6

[4] National Highway Traffic Safety Administration. Federal motor vehicle safety standards; tire pressure monitoring systems; controls and displays [R]. NHTSA-2000-8572, 2000.

[5] Ramakrishnan R, Gehrke J. Database management systems[M]. Osborne/McGraw-Hill, 2000.

[6] Bi Jun, Li Jian, Zhang Bing. IMSP: Integrated management system for water pollutant discharge permit based on a hybrid C/S and B/S model[J], Environmental Modelling \& Software, 2011, 26(6):831-833.

[7] Xin X. Research of Network Management Platform Based on BS Structure[C]//Applied Mechanics and Materials. 2014, 539: 291-295.

[8] Li Enlin. System analysis and design of MIS based on mixed model[J]. Information Technology, 2007, 31(6): 99-101.

[9] Hong-liang L, Hong-bin W, Hong-yu Q, et al. Design and Implementation of Stud-farm Daily Management System Based on C/S Structure[J]. Journal of Northeast Agricultural University (English Edition), 2014, 21(3): 50-59.

[10] Shao Yanling, Yuan Dongfeng. Information management system for sports meetings based on C/S and B/S models[J]. Journal of Nanyang Normal University, 2005, 4(9): 90-92.

[11]Wang Xiaoyong. An exploration into distributed MIS based campus network[J]. Radio Engineering, 2001, 31(8): 21-24. 